\title{
Fatigue life prediction in composites
}

\author{
R. J. Huston \\ Division of Aeronautical Systems Technology, CSIR, Pretoria, Republic of South Africa
}

\begin{abstract}
Because of the relatively large number of possible failure mechanisms in fibre reinforced composite materials, the prediction of fatigue life in a component is not a simple process. Several mathematical and statistical models have been proposed, but the experimental evidence to support them is limited so far. In this paper, an attempt has been made to fit experimental results to two of the more promising models. Results obtained from repeated tension fatigue tests on unidirectional carbon fibre reinforced epoxy were used to test residual strength and residual stiffness models. Further fatigue tests were carried out under spectrum loading so that the results could be correlated with the cumulative damage predicted by the residual strength model.
\end{abstract}

\section{INTRODUCTION}

During the last two decades or so, the use of composite materials in the place of metals in many industries has become widespread, not least in the aircraft industry. In general, a composite material can be defined as a material that consists of two or more distinct components. The composite materials used to manufacture aircraft structures have usually comprised continuous fibres embedded in a polymeric matrix. The fibres provide the strength and the stiffness and the matrix holds the fibres together. Considerable weight savings can be achieved by using composite materials in aircraft because of their higher specific strengths and specific stiffnesses compared with aluminium alloys.

Since the days of the Comet, fatigue has been a subject of considerable interest to the aircraft industry. The increased use of composite materials has emphasised the fact that their fatigue behaviour is more complex than the fatigue behaviour of metals. In a metal, fatigue damage eventually appears as a clearly defined crack, the initiation and propagation of which can be predicted by fracture mechanics analysis. In a composite material, fatigue damage can take the form of any or all of the following: delamination, matrix cracking, fibre failure, matrix crazing, fibre/matrix debonding and void growth. It is dependent on variables associated with the testing conditions and the construction and composition of the material.

The S-N curve appears still to be the most popular method of characterising the fatigue behaviour of composite materials. Several empirical equations exist for describing $\mathrm{S}-\mathrm{N}$ curves. Most are based on the classical power law that gives a straight line in a log-log plot of the fatigue data, but some possess refinements to account for mean stress or the ratio of maximum stress to minimum stress. One of the simpler equations used to describe the fatigue behaviour of several composite materials is as follows: ${ }^{1}$

$$
\sigma_{\mathrm{a}}=\sigma_{\mathrm{u}}-b \log N
$$

where $\sigma_{\mathrm{a}}$ is the maximum applied stress, $\sigma_{\mathrm{u}}$ is the static strength, $b$ is a constant and $N$ is the number of cycles to failure.

Other theories have been formulated for the characterisation of the fatigue behaviour of composite materials. There are essentially three types: theories based on the degradation of residual strength, theories based on changes in modulus and theories based on actual damage mechanisms.

Most of the life prediction methods for polymeric composite materials currently in favour are based on residual strength degradation (e.g. Refs 2-5).

These have been developed on the basis of 
three assumptions:

(1) the statistical variability of the static strength of the material can be described by a two-parameter Weibull distribution;

(2) the residual strength after $N$ cycles of fatigue loading can be related to the static strength by a deterministic equation; and

(3) when the residual strength decreases to the maximum applied stress, fatigue failure occurs.

Reduction in stiffness caused by fatigue loading has been reported by various observers, ${ }^{6-11}$ and it has been recently reviewed by Reifsnider. ${ }^{12}$ Theories for fatigue based on the reduction in stiffness have one significant advantage over the residual strength theories, namely that the remaining life can be assessed by non-destructive means.

A second advantage is that less testing needs to be conducted. A typical reduction in stiffness model $^{11}$ relates the degradation of modulus to the fraction of life expended at a given stress amplitude, assuming that the residual stiffness decreases monotonically as the number of load cycles increases.

Fatigue theories based on damage mechanisms model the intrinsic defects in the matrix as small cracks parallel to the fibres, and the propagation of these cracks are predicted by linear fracture mechanics analysis. Unfortunately, prediction of fatigue failure is difficult because sophisticated mathematical techniques are needed to calculate the forces required to propagate the cracks and the damage accumulation process is simulated using Monte Carlo methods. ${ }^{13}$

In this paper an attempt is made to correlate the fatigue theories of Sendeckyj ${ }^{5}$ and Whitworth ${ }^{11}$ with the experimental results obtained from unidirectional carbon fibre reinforced epoxy.

\section{EXPERIMENTAL PROCEDURE}

\section{Composite material tested and its processing conditions}

The composite material system used to test the residual strength and residual stiffness models was a unidirectional carbon fibre reinforced epoxy prepreg system, Vicotex 913C-TS, manufactured by Brochier SA, an affiliate of
Ciba-Geigy. The resin matrix was a modified epoxy with good resistance to temperature and humidity, and the carbon fibres were of the Torayca T300B type.

The standard autoclave curing schedule was applied to manufacture the sheets from which test specimens could be prepared. This schedule consisted of heating the uncured laminate under vacuum to $90^{\circ} \mathrm{C}$ at a rate of about $3^{\circ} \mathrm{C}$ per minute and then holding the temperature at $90^{\circ} \mathrm{C}$ for $30 \mathrm{~min}$. A pressure of 7 bar was gradually applied and the vacuum vented when the pressure reached 1.4 bar. The temperature was increased to $120^{\circ} \mathrm{C}$, again at about $3^{\circ} \mathrm{C}$ per minute, and held there for $60 \mathrm{~min}$. The laminate was then cooled to $90^{\circ} \mathrm{C}$ when the pressure was released, and it was removed from the autoclave when the temperature had dropped to below $60^{\circ} \mathrm{C}$.

\section{Preparation of specimens}

The same type of specimen was used in the tensile and fatigue tests. It was a flat, parallel-sided specimen approximately $220 \mathrm{~mm}$ long, $20 \mathrm{~mm}$ wide and $1 \mathrm{~mm}$ thick. A band saw was used to cut the specimens out of the cured laminates, and they were ground parallel with the aid of a surface grinder. To facilitate load transfer in the grips of the test machine, aluminium tabs about $2 \mathrm{~mm}$ thick were bonded on to each specimen.

\section{Test programme}

In the first stage of the test programme, tensile tests were conducted on 30 specimens to place an upper limit on the stress levels to be applied in the subsequent fatigue tests and to assess the variability in the properties of the material. The tensile tests were conducted in accordance with the recommendations of ASTM D3039, and in each test the tensile strength and the tensile modulus were measured.

Following the tensile tests, fatigue tests were carried out to derive $\mathrm{S}-\mathrm{N}$ curves for the material. These tests were carried out under load control in repeated tension with the stress ratio $(R)$ equal to $0 \cdot 1$. The frequency was $10 \mathrm{~Hz}$. Five replicate specimens were tested at each of seven stress levels to generate the $\mathrm{S}-\mathrm{N}$ curves. Five tensile strength results, selected randomly from the tensile test data, were also included. The failure criterion was considered to be specimen fracture. 
Fatigue tests were continued until approximately 2 million cycles, at which point the specimens were considered to be run-outs. Tensile tests were conducted on each run-out to measure residual strength.

At two stress levels, 1700 and $1800 \mathrm{MPa}$, further fatigue tests were carried out to assess the variability of fatigue life. Twenty-five specimens were tested at both stress levels to identify a probable distribution.

In the next stage of the programme, a series of load spectrum tests was performed to compare cumulative damage predictions with experimental results. A load spectrum based on FALSTAFF ${ }^{14}$ was devised and 10 specimens tested. The tests were continued either to failure or were stopped after 5 million cycles, and then residual tensile strength was measured. As before, the tests were carried out under load control at a frequency of $10 \mathrm{~Hz}$ and with a stress ratio $(R)$ of $0 \cdot 1$.

Finally, to assess the residual modulus model, a few more fatigue tests were performed. At various stages in each of these tests, the static tensile modulus was measured. To do this, the fatigue tests were interrupted periodically so that an extensometer could be attached to the specimen and the measurements made.

\section{Test equipment}

All the fatigue tests were conducted using a Schenck Hydropuls machine of $250 \mathrm{kN}$ capacity. Tensile modulus measurements were made using an HBM DD1 strain transducer connected to an HBM DWS73 amplifier and digital monitor.

\section{TENSILE TEST RESULTS}

The results of the preliminary tensile tests are summarised in Table 1 . The tensile strength data were analysed in the manner recommended in the Military Handbook 17B, and a twoparameter Weibull distribution was found to be the most appropriate, in preference to the normal, log-normal, and non-parametric distributions. As can be seen from the Weibull plot in Fig. 1, the linearity of the results is questionable, as borne out by the correlation coefficient of -0.92 . The distribution of the tensile moduli is shown in Fig. 2. The data fit the Normal distribution well.

\section{GENERATION OF FATIGUE CURVES}

The most popular method of characterising the fatigue behaviour of composite materials is still the generation of $\mathrm{S}-\mathrm{N}$ curves. To attach statistical value to these curves, it has usually been necessary to test large numbers of replicate specimens at different stress levels to obtain the distribution of fatigue lives. Examples of this are shown in Figs 3 and 4, where Weibull distributions have been fitted to fatigue lives obtained at maximum stresses of 1700 and $1800 \mathrm{MPa}$.

The probabilistic life prediction model of Sendeckyj ${ }^{5}$ does not require a large data base. Static, fatigue and residual strengths are all converted to equivalent static strengths and pooled to produce a data base large enough for statistical analysis. A two-parameter Weibull distribution is fitted to the residual strength data. By assuming that the shape $(\alpha)$ and scale $(\beta)$ parameters of the fatigue life and static strength distributions are functionally related to each other and to the constants $C$ and $S$ in the classical fatigue power law equation

$$
\sigma_{\mathrm{u}} / \sigma_{\mathrm{a}}=C N^{s}
$$

Table 1. Tensile strength and tensile modulus results for unidirectional Vicotex 913C-TS carbon fibre reinforced epoxy

\begin{tabular}{lcc}
\hline & $\begin{array}{c}\text { Tensile } \\
\text { strength, } S_{11^{+}} \\
(\mathrm{MPa})\end{array}$ & $\begin{array}{c}\text { Tensile } \\
\text { modulus, } E_{11^{+}} \\
(\mathrm{GPa})\end{array}$ \\
\hline Mean & 2180 & 135 \\
Standard deviation & 197 & $5 \cdot 89$ \\
Coefficient of variation & $0 \cdot 090$ & $0 \cdot 004$ \\
No. of specimens & 30 & 30 \\
Maximum value & 2526 & 148 \\
Minimum value & 1733 & 122 \\
Distribution & Weibull & - \\
B-Basis value & 1800 & - \\
A-Basis value & 1700 & - \\
\hline
\end{tabular}




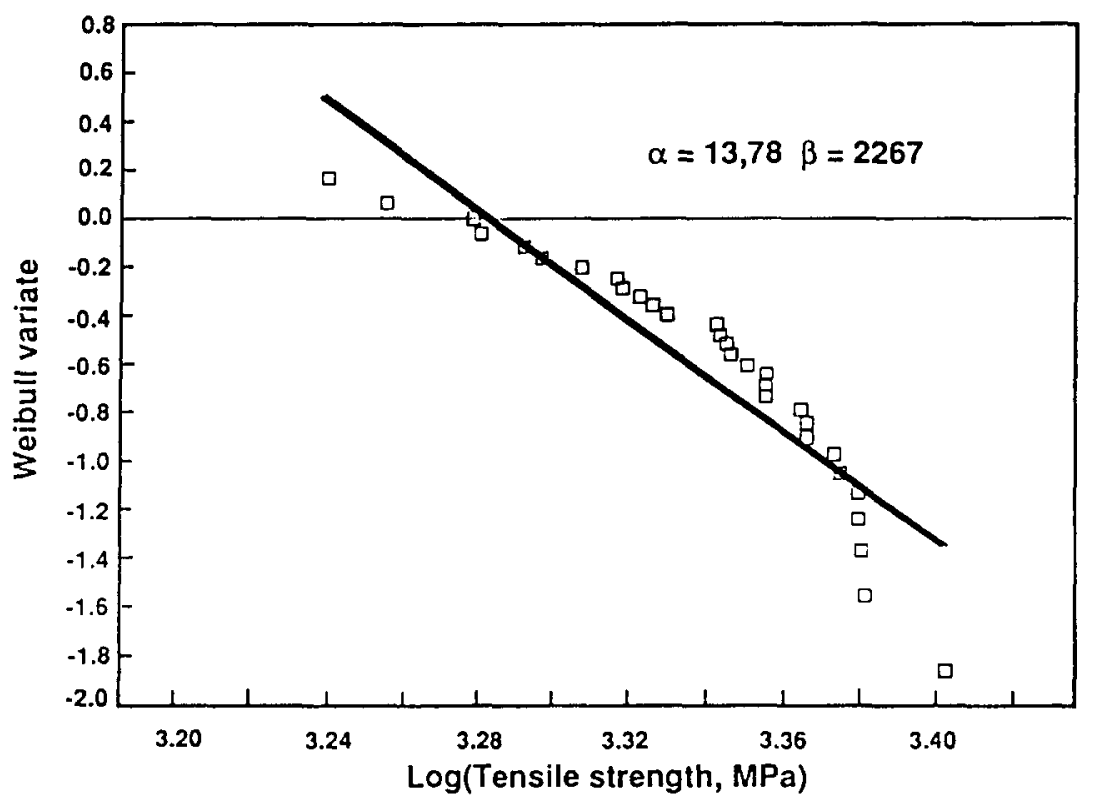

Fig. 1. Weibull distribution of tensile strengths.

the following expression for fatigue life can be obtained:

$$
\sigma_{c}=\left[\sigma_{r}^{1 / S}+C(N-1) \sigma_{a}^{1 / S}\right]^{S}
$$

where $\sigma_{\mathrm{e}}$ is the equivalent static strength.

Fitting the fatigue model to the experimental data is an iterative process. From the $\log \sigma$ versus $\log N$ plot shown in Fig. 5, initial values of $C$ and $S$ are estimated. The fatigue data are converted to equivalent static data by using these values in eqn (3). A two-parameter Weibull distribution is then fitted to the $\sigma_{\mathrm{e}}$ data, preferably by using the maximum likelihood method, and the values of the shape and scale parameters are stored. New values for $C$ and $S$ are chosen and the procedure is repeated until the maximum value of the shape parameter is obtained. This value, and the corresponding scale, $C$ and $S$ values, provide the best fit of the fatigue data. For the fatigue tests reported here, the values of $C$ and $S$ were found to be 0.00075 and 0.0576 , respectively. These gave rise to a shape parameter of 13.24 and a scale parameter of 2235 for the distribution of the equivalent static strengths. This distribution is shown in Fig. 6. From this distribution and eqn (3), S-N curves

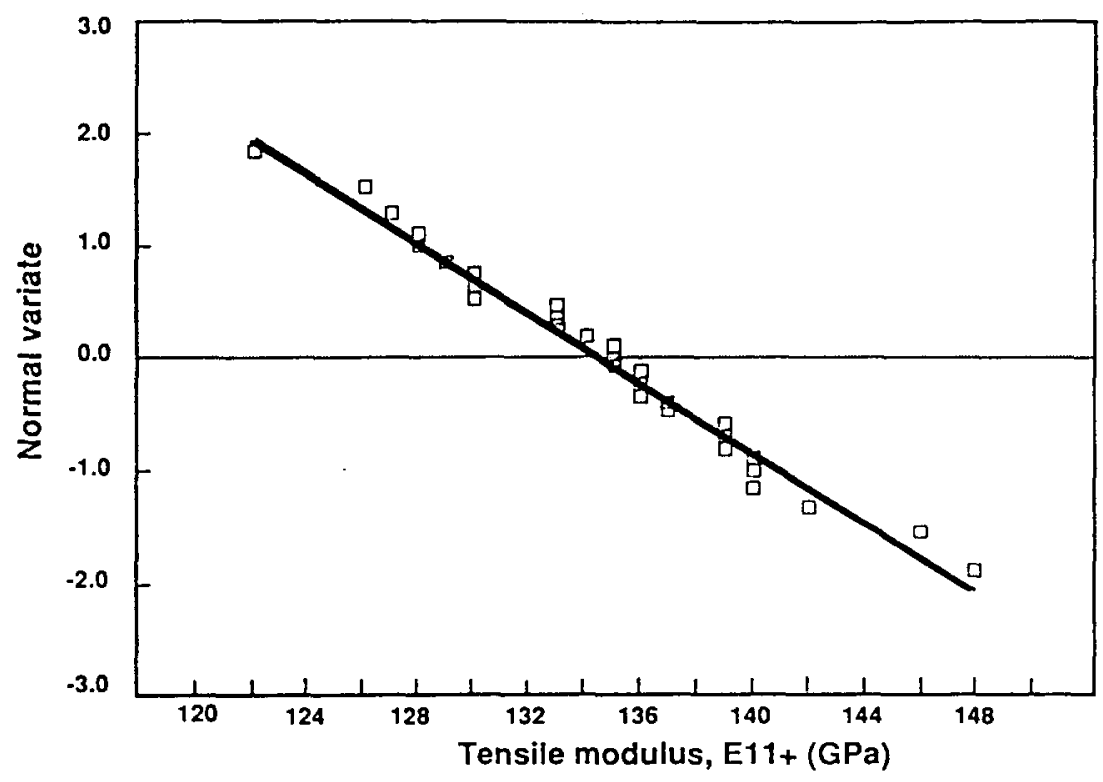

Fig. 2. Normal distribution of tensile moduli. 


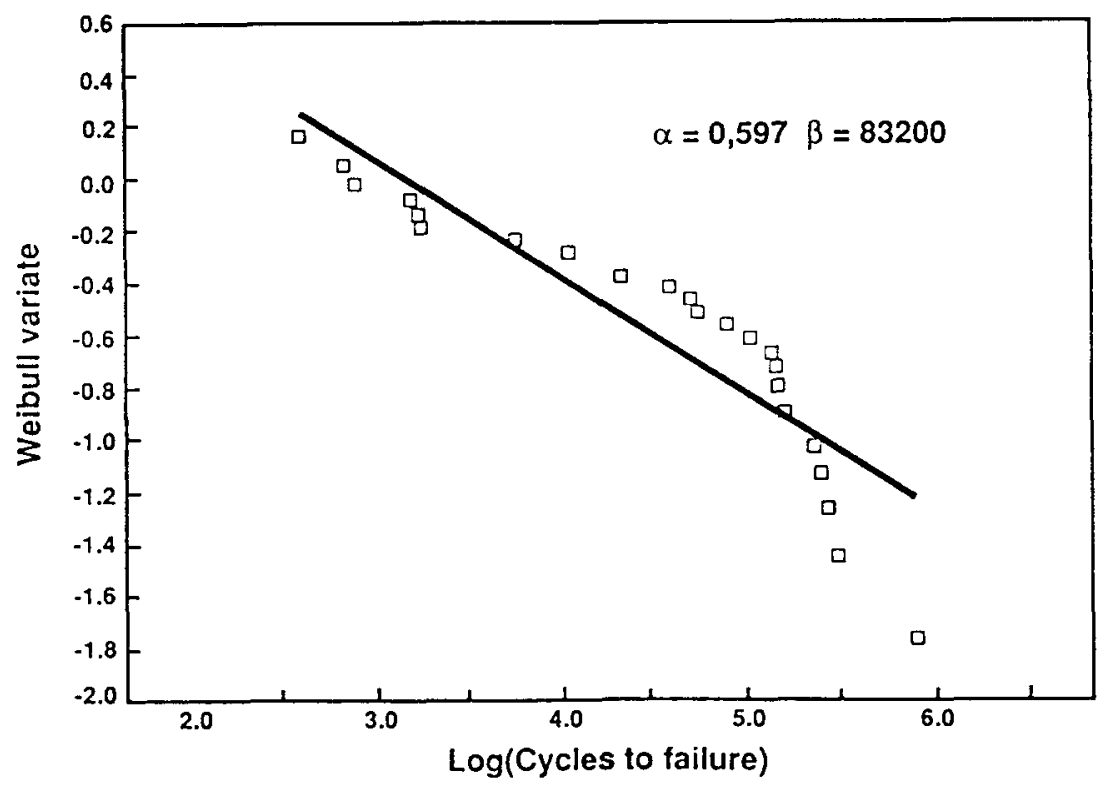

Fig. 3. Weibull distribution of fatigue lives at maximum stress of $1700 \mathrm{MPa}$.

can be constructed for various probabilities of survival. Examples of these are shown in Fig. 7.

The Sendeckyj model is a convenient method of describing fatigue behaviour but is dependent on the validity of the three assumptions upon which it is based: ${ }^{5}$

(1) the $\mathrm{S}-\mathrm{N}$ behaviour can be described by a deterministic equation;

(2) the static strengths are uniquely related to the fatigue lives and residual strengths after a specific number of cycles; and
(3) the static strength data can be described by a two-parameter Weibull distribution.

For the fatigue tests presented here, the first assumption is probably valid, since an empirical equation can be fitted to the data. The second assumption could be invalidated if different failure modes were possible, but this is unlikely in this investigation as the stress distribution resulting from tensile loads applied in the longitudinal direction to a unidirectionally reinforced specimen is not complex. The linearity

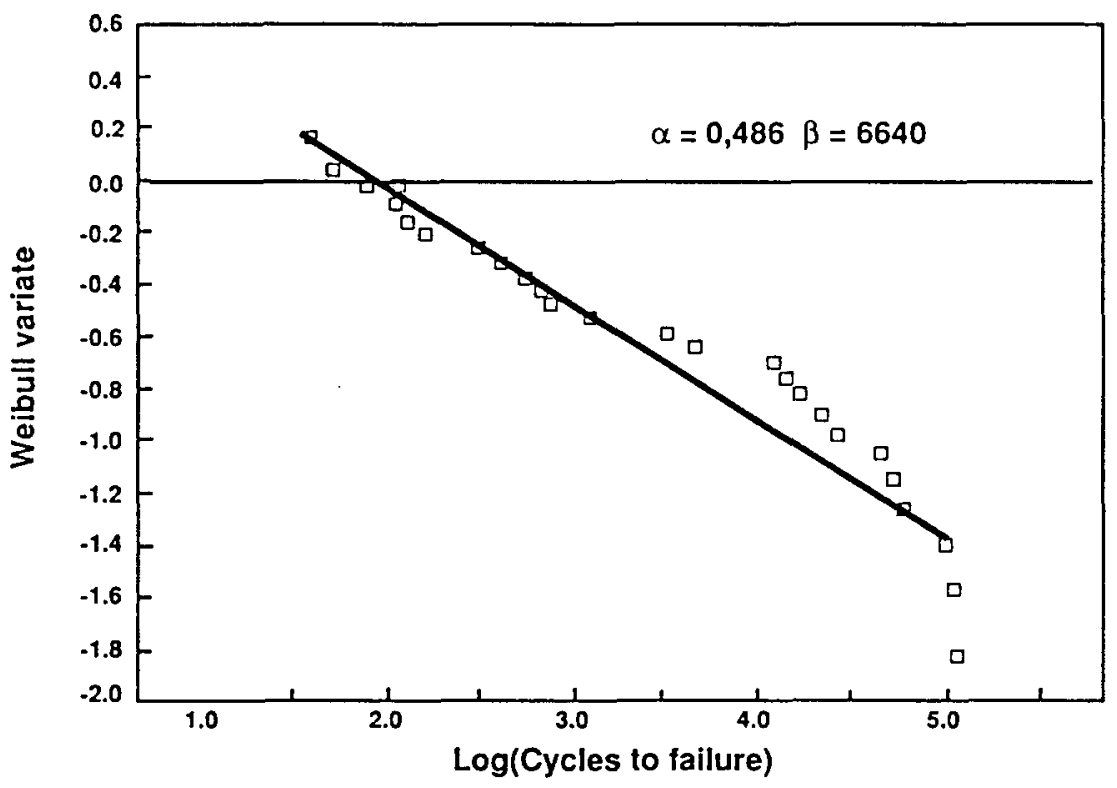

Fig. 4. Weibull distribution of fatigue lives at maximum stress of $1800 \mathrm{MPa}$. 


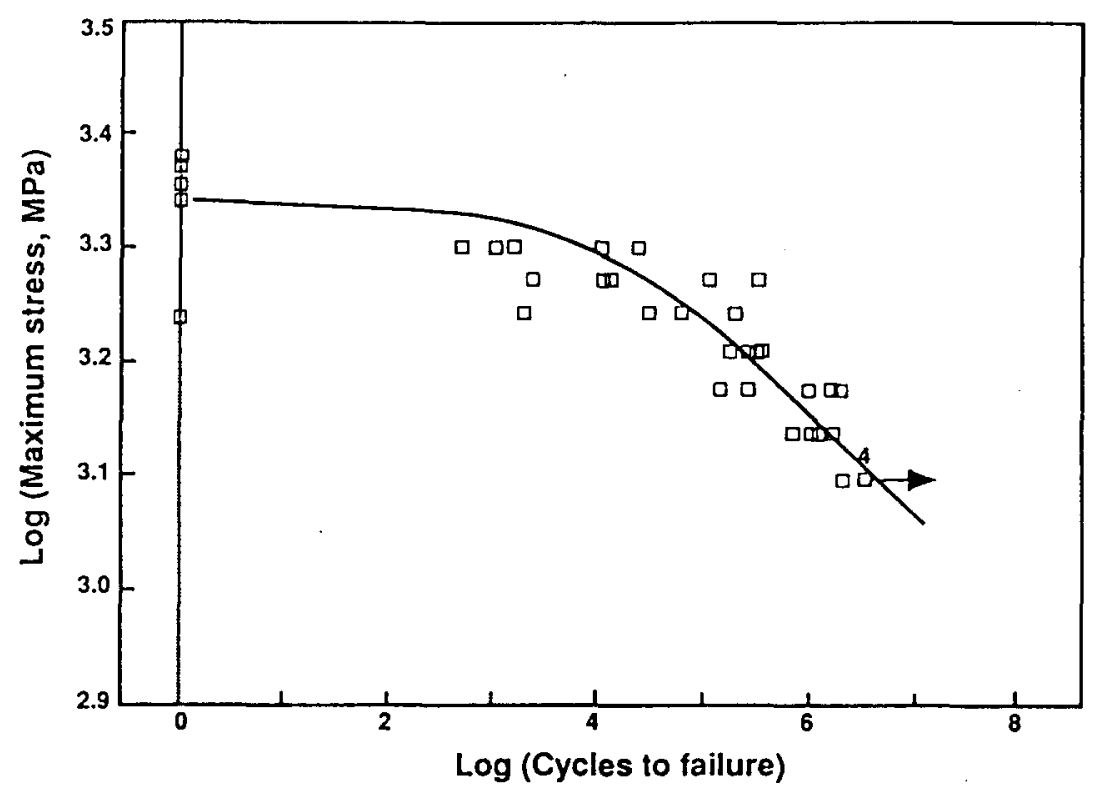

Fig. 5. Fatigue curve for Vicotex 913C-TS.

of the data in Fig. 6 provides an indication of the validity of the third assumption. The correlation coefficient is -0.96 . This suggests that the Weibull distribution fits the equivalent static strength data quite well.

\section{FATIGUE LIFE PREDICTION UNDER SPECTRUM LOADING}

If one rearranges eqn (3) to

$$
\sigma_{\mathrm{r}}=\left[\sigma_{\mathrm{c}}^{1 / S}-C(N-1) \sigma_{\mathrm{a}}^{1 / S}\right]^{S}
$$

and if one makes the assumption that this equation can generate a value for residual strength after every cycle, Sendeckyj's model can be applied to spectrum loading.

The fatigue load spectrum used in this investigation was based on FALSTAFF, but it was simplified and a factor was used on the loads to ensure that some specimens failed after not too many cycles. The spectrum is given in Table 2.

An example of how the residual strength model can be applied to predict the fatigue life of a specimen under spectrum loading is shown in

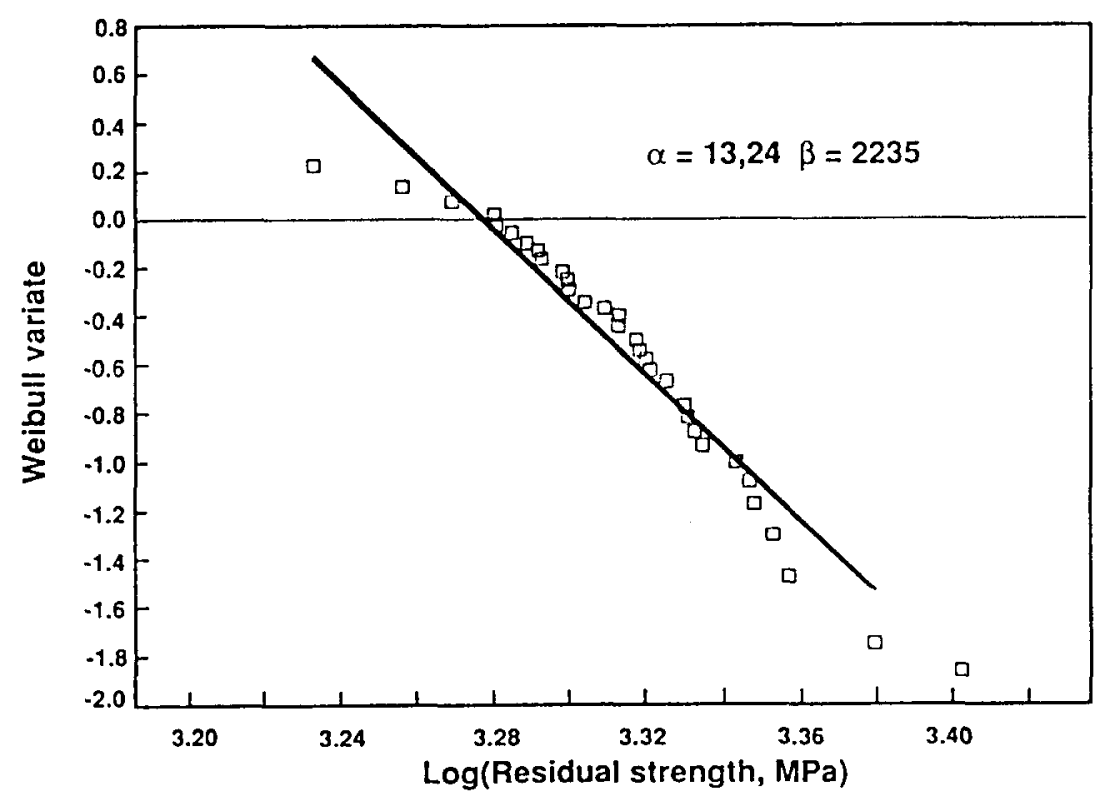

Fig. 6. Weibull distribution of equivalent static strengths. 


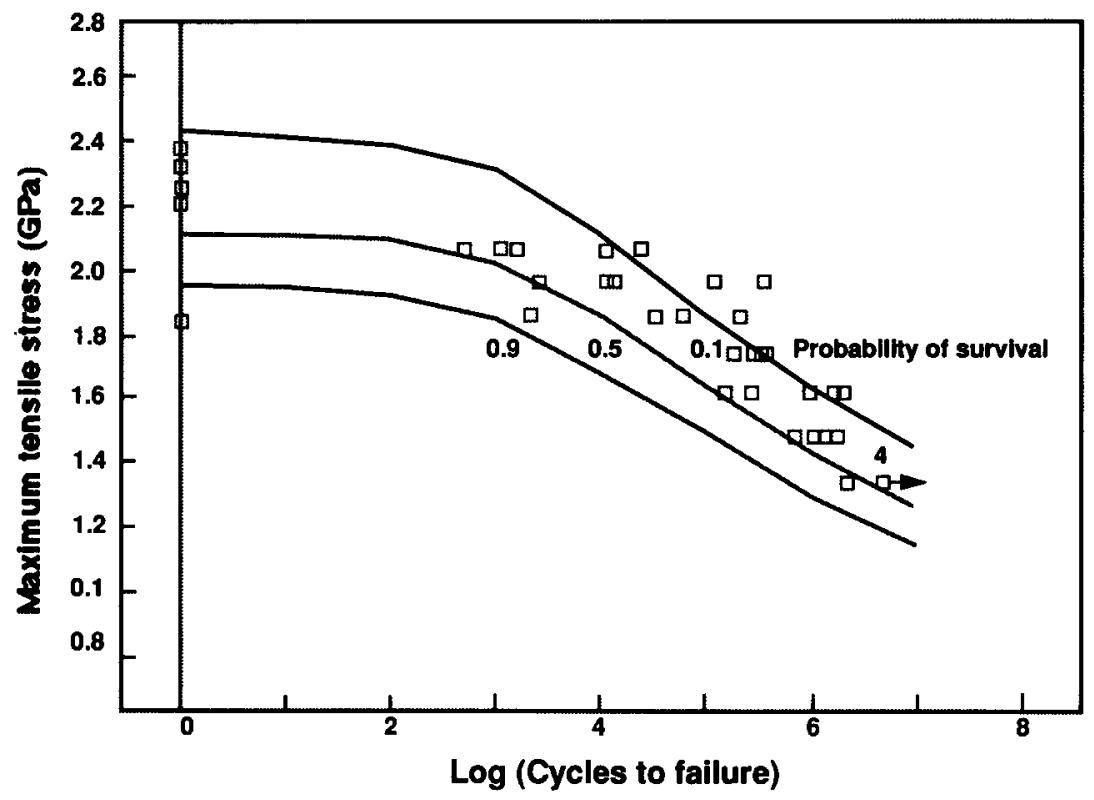

Fig. 7. S-N curves for $0.9,0.5$ and 0.1 probabilities of survival.

Table 2. Fatigue spectrum

\begin{tabular}{cr}
\hline Maximum stress (MPa) & Number of cycles \\
\hline 1480 & 8100 \\
1200 & 50000 \\
990 & 225000 \\
1310 & 23000 \\
1800 & 500 \\
1630 & 1900 \\
1100 & 150000 \\
850 & 1000000 \\
\hline
\end{tabular}

Table 3. For a probability of survival of 0.9 , the equivalent tensile strength is $1945 \mathrm{MPa}$. The residual strength decreases progressively through each stage of each block. The value after each stage is given in Table 3 . When the residual strength has decreased to a value below the applied stress, failure occurs. This is predicted to happen after 4576600 cycles, when the maximum applied stress is $1800 \mathrm{MPa}$ in the fourth block.

Some experimental results are presented in Table 4 for comparison with the residual strength model prediction. As can be seen, two specimens had fatigue lives shorter than that predicted, one considerably so, while eight specimens survived 5 million cycles. Specimen 4 failed during the $1800 \mathrm{MPa}$ stage of the third block, and Specimen 7 failed during the $1630 \mathrm{MPa}$ stage of the first block. The residual tensile strengths were measured for the other specimens and quite a wide variation was observed. Naturally, all were higher than the highest maximum applied stress of the fatigue spectrum.

The predicted fatigue life was for a probability of survival of $0 \cdot 9$, so one would expect one

Table 3. Fatigue life prediction: residual strength model

\begin{tabular}{cccccc}
\hline $\begin{array}{c}\text { Maximum stress, } \sigma_{\mathrm{a}} \\
(\mathrm{MPa})\end{array}$ & Number of cycles, $N$ & \multicolumn{4}{c}{$\begin{array}{c}\text { Residual strength after } N \text { cycles, } \sigma_{\mathrm{r}} \\
(\mathrm{MPa})\end{array}$} \\
\cline { 3 - 6 } & & & \multicolumn{4}{c}{ 1st block } & 2nd block & 3rd block & 4th block \\
\hline 1480 & 8100 & 1939 & 1905 & 1857 & 1772 \\
1200 & 50000 & 1938 & 1904 & 1855 & 1768 \\
990 & 225000 & 1938 & 1903 & 1855 & 1769 \\
1310 & 23000 & 1936 & 1901 & 1850 & 1757 \\
1800 & 500 & 1923 & 1883 & 1822 & Failure \\
1630 & 1900 & 1914 & 1870 & 1798 & - \\
1100 & 115000 & 1913 & 1869 & 1797 & - \\
850 & 1000000 & 1913 & 1869 & 1797 & - \\
\hline
\end{tabular}

Equivalent tensile strength $=1945 \mathrm{MPa}$.

Number of cycles to failure $=4576600$. 
Table 4. Fatigue spectrum test results

\begin{tabular}{rcc}
\hline Specimen & $\begin{array}{c}\text { Fatigue life } \\
\text { (cycles) }\end{array}$ & $\begin{array}{c}\text { Residual strength } \\
\text { (MPa) }\end{array}$ \\
\hline 1 & - & 2322 \\
2 & - & 2098 \\
3 & - & 2094 \\
4 & 3153350 & - \\
5 & - & 2450 \\
6 & - & 1908 \\
7 & 308390 & 1834 \\
8 & - & 2166 \\
9 & - & 1971 \\
10 & - & - \\
\hline
\end{tabular}

specimen in ten to have a shorter than predicted life. When the tests were carried out, two specimens out of the ten had lives shorter than predicted. Considering the small sample, the correlation is adequate.

\section{RESIDUAL STIFFNESS MODEL}

The residual stiffness model of Whitworth is a phenomenological model and is limited to specimens subjected to constant amplitude fatigue loading. The model requires the calculation of three parameters from experimental data, and it is assumed that residual stiffness decreases monotonically as the number of cycles increases.

The basis of the model is an equation that assumes that the rate of the residual modulus reduction is inversely proportional to a power of the residual modulus itself:

$$
\frac{\mathrm{d} E\left(N^{\prime}\right)}{\mathrm{d} N^{\prime}}=\frac{-D \mathrm{f}^{x}\left(E(0), \sigma_{\mathrm{a}}\right)}{x E^{x-1}\left(N^{\prime}\right)}
$$

where $E\left(N^{\prime}\right)$ is the residual modulus after $N$ fatigue cycles, $N^{\prime}$ is the ratio of the applied cycles to the fatigue life, $E(0)$ is the initial modulus, $x$ and $D$ are constants and $\mathrm{f}\left(E(0), \sigma_{\mathrm{a}}\right)$ is a function of the initial modulus and the stress range, $\sigma_{\mathrm{a}}$.

Integration of eqn (5) from 0 to $N^{\prime}$ :

$$
E^{x}\left(N^{\prime}\right)=E^{x}(0)-D f^{x}\left(E(0), \sigma_{\mathrm{a}}\right) N
$$

and this represents the residual modulus after a certain portion of the fatigue life has been completed.

If it is assumed that $\mathrm{f}\left(E(0), \sigma_{\mathrm{a}}\right)$ is a linear function of the stiffness change over the cyclic life

$$
\mathrm{f}\left(E(0), \sigma_{\mathrm{a}}\right)=k \Delta E\left(N^{\prime}\right)
$$

and if the stress-strain response is linear to failure, then at failure

$$
E\left(N^{\prime}\right)=E_{\mathrm{f}} \text { and } \sigma_{\mathrm{a}}=E_{\mathrm{f}} e_{\mathrm{f}}
$$

where $E_{\mathrm{f}}$ is the reduced stiffness at failure and $e_{\mathrm{f}}$ is a constant related to the strain at failure. Equation (6) becomes

$$
\begin{aligned}
E^{x}\left(N^{\prime}\right) & =E^{x}(0)-D k^{x}\left[E(0)-\sigma_{\mathrm{a}} / e_{\mathrm{f}}\right]^{x} N^{\prime} \\
& =E^{x}(0)-H[E(0)-B]^{x} N^{\prime}
\end{aligned}
$$

where $H=D k^{x}$ and $B=\sigma_{\mathrm{a}} / e_{\mathrm{f}}$.

As can be seen in eqn (9), three parameters $(x, H$ and $B$ ) characterise the stiffness reduction and are determined experimentally. $x$ and $H$ are independent of the test variables and $B$ is dependent on the maximum applied stress. More details of the model can be found in Refs 11 and 15.

To determine the constants $x, H$ and $B$, fatigue tests were carried out on five specimens. During each test the static modulus was measured on several occasions. The reduction in modulus for all five specimens is plotted against cycles in Fig. 8. The modulus after $N$ cycles is given as a fraction of the initial modulus and the number of cycles is given as a fraction of the fatigue life. The maximum stress was $1875 \mathrm{MPa}$ and the fatigue lives varied from 2520 cycles to 344310 cycles. Figure 8 shows that the reduction in modulus, though slight, is almost linear up to a fractional life of about 0.75 , after which the decrease is a little more rapid. However, the maximum observed drop was only $6 \%$, from 135 to about $127 \mathrm{GPa}$.

The values of the constants $x, H$ and $B$ were found to be $1.15,1.74$ and 127 , respectively.

The curve generated by eqn (9) appears to fit the experimental results quite well. The measured reduction in stiffness was rather small and perhaps unidirectional carbon reinforced epoxy was not the correct material to test the model. However, one can clearly see the necessity for accurate modulus measurement if the model is to be applied successfully.

\section{CONCLUSIONS}

The residual strength model of Sendeckyj and the residual stiffness model of Whitworth have been used to describe the repeated tension fatigue properties of unidirectional carbon fibre reinforced epoxy. Both models fitted the experimental results quite well. 


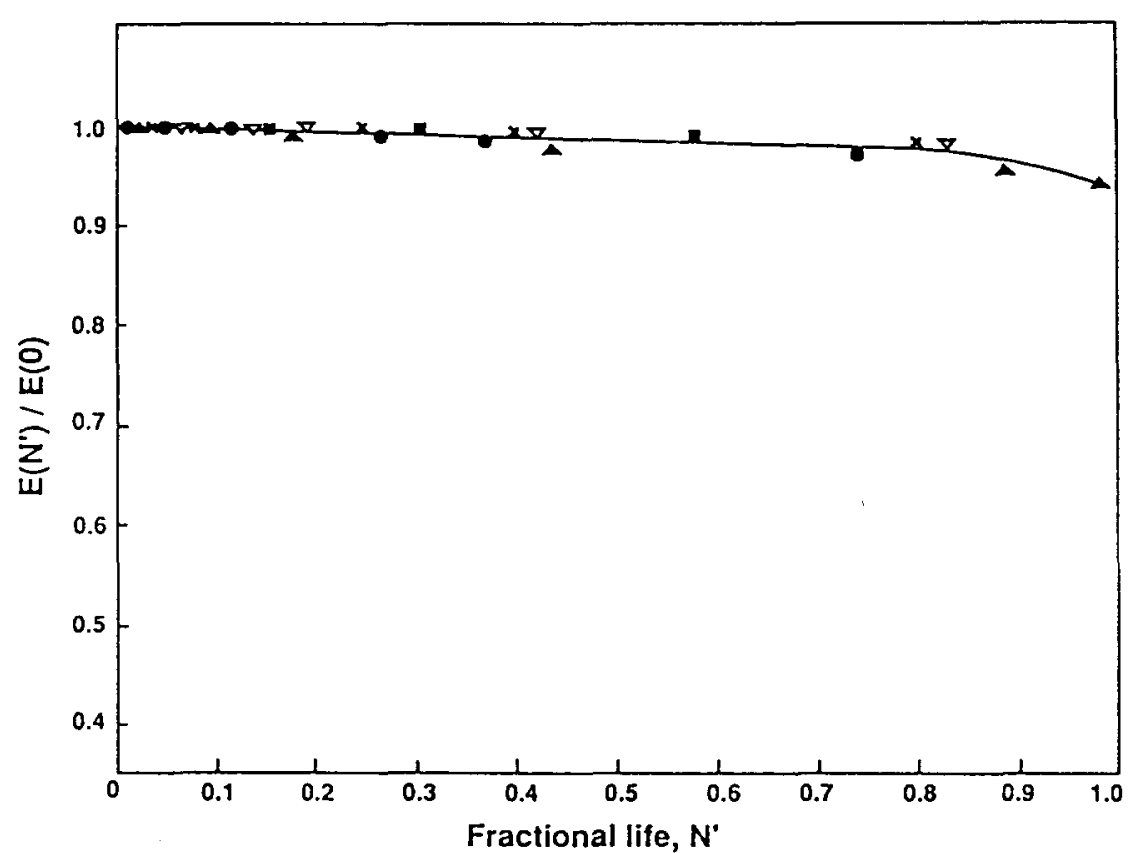

Fig. 8. Normalised static modulus as a function of the fraction of fatigue life at a maximum stress of $1875 \mathrm{MPa}$.

The residual strength model was also used to predict fatigue life under spectrum loading. The correlation between the prediction and the experimental observations was satisfactory.

If the assumptions on which the residual strength model is based are shown to be valid, then the model can be used with some confidence. The parameters $C$ and $S$ are probably dependent on factors like laminate orientation, environmental conditions and $R$-ratio, so the model would need to be modified to accommodate these. However, work carried out at Northrop has indicated that, if strain is used to define fatigue load instead of stress, less modification is required. ${ }^{16}$

The residual stiffness model also provided a reasonable fit to the experimental results obtained. It should prove to be a useful tool in monitoring fatigue life, as long as the modulus is measured accurately. Its main disadvantage is that it can be applied only to constant amplitude fatigue loadings.

\section{REFERENCES}

1. Mandell, J. F., Huang, D. D. \& McGarry, F. J., Tensile fatigue performance of glass fibre dominated composites. Comp. Technol. Rev., 3 (1981) 96-102.

2. Halpin, J. C., Jerina, K. L. \& Johnson, T. A., Characterization of composites for the purpose of reliability evaluation. In Analysis of Test Methods for
High Modulus Fibres and Composites (ASTM STP 521). ASTM, Philadelphia, PA, 1973, 5-64.

3. Yang, J. N., Reliability prediction for composites under periodic proof tests in service. In Proceedings of 4 th Conference on Composite Materials: Testing and Design (ASTM STP 617). ASTM, Philadelphia, PA, 1977, 272-95.

4. Whitney, J. M., Residual strength degradation model for competing failure modes. In Long Term Behaviour of Composites (ASTM STP 813). ASTM, Philadelphia, PA, 1983, 483-97.

5. Sendeckyj, G. P., Fitting models to composite materials fatigue data. In Test Methods and Design Allowables for Fibrous Composites (ASTM STP 734). ASTM, Philadelphia, PA, 1981, 245-60.

6. Componeschi, E. T. \& Stinchcomb, W. W., Stiffness reduction as an indicator of damage in graphite/epoxy laminates. In Composite Materials: Testing and Design (Sixth Conference) (ASTM STP 787). ASTM, Philadelphia, PA, 225-46.

7. Schulte, K., Stiffness reduction and development of longitudinal cracks during fatigue loading of composite laminates. In Mechanical Characterization of Load Bearing Fibre Composite Laminates, ed. A. H. Cardon \& G. Verchery. Elsevier Applied Science Publishers, London, 1985, pp. 36-54.

8. Yang, J. N., Jones, D. L., Yang, S. H. \& Meskini, A., A stiffness degradation model for graphite/epoxy laminates. In Proceedings of AIAA/ASME/ ASCE/AHS 29th Structures, Structural Dynamics and Materials Conference, Williamsburg, Virginia, 1988, 958-66.

9. Rotem, A., Stiffness change of a graphite epoxy liminate under reverse fatigue loading. J. Comp. Technol. Res., 11 (1989) 59-64.

10. Naeem, M., Fatigue damage-compliance relationship for GRP. Composites, 20 (1989) 589-92.

11. Whitworth, H. A., Modelling stiffness reduction of graphite/epoxy composite laminates. J. Comp. Mater., 21 (1987) 362-72. 
12. Reinfsnider, K. L., Damage and damage mechanics. In Fatigue of Composite Materials, ed. K. L. Reifsnider. Elsevier Science Publishers, Amsterdam, The Netherlands, 1990, pp. 11-77.

13. Wang, A. S. D., Chou, P. C., Lei, C. S. \& Bucinell, R. B., Cumulative damage model for advanced composite materials, AFWAL-TR-85-4104. Wright-Patterson Air Force Aeronautical Laboratory, Dayton, OH, 1985.

14. Van Dijk, G. M. \& De Jonge, J. B., Introduction to FALSTAFF. In Proceedings of \&th ICAF Symposium, International Committee on Aeronautical Fatigue,
Lausanne, 1975, 3.61/1-39.

15. Whitworth, H. A., Static and dynamic stiffness reduction of graphite/epoxy composite laminates under fatigue loading. DSc Thesis, George Washington University, Washington DC, 1983.

16. Jeans, L. L., Deo, R., Grimes, G. C. \& Whitehead, R. S., Durability certification of fighter aircraft primary composite structure. In Proceedings of 11th ICAF Symposium, International Committee on Aeronautical Fatigue, Noordwijkerhout, 1981, 3.1/1-54. 